\title{
Bacteriophage Morphological Characterization by Using Transmission Electron Microscopy
}

\author{
Giuseppe Aprea, Anna Rita D’Angelo, Vincenza Annunziata Prencipe and Giacomo Migliorati \\ Department of Hygiene in Food Technology and Animal Feeds, Istituto Zooprofilattico Sperimentale dell'Abruzzo e del Molise "G. \\ Caporale", Teramo 64100, Italy
}

Received: April 3, 2015 / Accepted: May 6, 2015 / Published: May 30, 2015.

\begin{abstract}
Bacteriophages or more commonly "phages" are bacterial viruses. They are ubiquitous and good indicators of bacterial contaminations since their prevalence is high in those environments where their hosts are abundant. Phage classification is based on morphology and for this reason, even though it is considered an old technique, TEM (Transmission Electron Microscopy) still plays a key role in their characterization. In the present work, the authors focused on TEM analysis of phage $\Phi$ Apr-1 isolated against Lactococcus lactis (L. lactis), implicated in industrial fermentations and of phage $\Phi$ IZSAM-1, active against Listeria monocytogenes (L. monocytogenes), isolated from the environment. For observation with TEM (EM 900T-Zeiss), phages were harvested in liquid media and were negative stained with fosfotungstic acid $2 \%$. An accurate viral ultrastructure analysis by using TEM is fundamental not only in the first approach of characterization of newly isolated phages but also for providing useful information to go further to the selection process as potential bio-decontaminants.
\end{abstract}

Key words: Bacteriophages, bacteria, bio-decontaminants, morphology, pathogens, TEM (Transmission Electron Microscopy).

\section{Introduction}

Bacteriophages are viruses that recognise bacteria as their specific hosts. Lytic bacteriophages in particular are prokaryote's natural enemies, in fact, after having infected the cell, they lyse it as final consequence of their replication.

There are an estimated $10^{31}$ bacteriophages on the planet [1-4]. Their specificity for a particular bacterium is expressed towards the strain, the species and more rarely the genus level [3], while they are totally innocuous for eukaryotic cells, animals and humans $[5,6]$.

Early papers on bacteriophages are dated around the 20 's. At the beginning, phages were employed as diagnostic tools in bacteria [3, 7-15]. Lately they started to be used for prophylaxis and therapy both in animals and humans in Eastern Countries. Their

Corresponding author: Giuseppe Aprea, Ph.D., research fields: hygiene in food technology and animal feeds. E-mail: g.aprea@izs.it. natural anti-bacterial activity was scientifically and clinically confirmed and they were administered particularly in those cases were antibiotics failed.

Today bacteriophages are more and more recognised as safe, efficacious $[6,16]$ and innovative alternatives to the use of chemotherapies (phage-therapy) [17-19]. This would enable to prevent bacterial antibiotic resistance development. Moreover they are also identified as active substances to be used against unwanted bacteria for bio-decontamination in flocks and livestocks but also in hospitals and along the chain of food productions (bio-decontaminants) [3, 20].

Another aspect to take in consideration is the undesirable implication in cheese making when specific lactic phages infect and lyse LAB (lactic acid bacteria) which are indispensable for milk curdling [21, 22].

Since they are ubiquitous and their prevalence is high in the same environment where their hosts are 
abundant, bacteriophages can be considered good indicators of the presence of bacteria [23]. For instance it is clearly demonstrated the correlation between coliphages (phages active against Escherichia coli) and bacteria responsible of colibacillosis in animals [24].

Bacteriophages are differentiated on the bases of their morphology and for this reason TEM is still irreplaceable [25]. They present a great shape variability and their primary classification is based on six groups established from Bradley in 1967 [26]. The groups $\mathrm{A}, \mathrm{B}, \mathrm{C}, \mathrm{D}$ and $\mathrm{E}$ are distinguished according to head shape (icosahedral or elongated) and tail (presence or absence). In case of presence, the tail can be contractile or non-contractile and short or long when compared to head diameter. Some phages can also show appendices (tail-fibers). Filamentous phages, instead, belong to group F. From phage's ultrastructure it is also possible to define some genome characteristics (single/double DNA chains or single RNA chains) [26].

Another phage classification always based on morphology is used for Campylobacter lytic bacteriophages. In particular they are identified into three groups in relation to head diameter and genome size [27].

The present work focused on morphological characterization of one phage implicated in industrial fermentations ( $\Phi$ Apr-1active against $L$. lactis) and of another phage ( $\Phi \mathrm{IZSAM}-1)$ that is currently being assayed for future applications against $L$. monocytogenes.

$\Phi$ Apr-1 and $\Phi$ IZSAM-1 were morphologically compared with $\Phi \mathrm{P} 100$, a phage active against $L$. monocytogenes.

Moreover in the authors' study, they confirmed the positive correlation between phages and their hosts in the environment and we also demonstrate how a punctual TEM ultrastructure analysis of viral particles can contribute to their further selection process as bio-decontaminants.

\section{Materials and methods}

\subsection{Bacteriophages and Hosts}

The first phage to be assayed for morphological characterization was $\Phi$ Apr-1, active against $L$. lactis and implicated in cheese fermentation failures. The phage and its host were isolated from whey starter cultures used for the production of D.O.P. Italian water buffalo mozzarella cheese.

The second phage, $\Phi$ IZSAM-1, active against $L$. monocytogenes, was isolated from waste waters of a cheese plant that was monitored for $L$. monocytogenes contamination and where this pathogen was constantly detected. The host used for phage harvesting was $L$. monocytogenes ATCC 7644, serotype 1/2 c.

The third phage, $\Phi \mathrm{P} 100$, is also an anti-Listeria phage and it is commonly used in U.S.A. to prevent $L$. monocytogenes contamination in Ready To Eat food [28-32] as principal component of a product called Listex ${ }^{\mathrm{TM}}$ P100 (Micreos, Wageningen, Holland).

All bacteriophages were cultured in liquid media [33] for $24 \mathrm{~h}$ and filtered with $0.45 \mu \mathrm{m}$ filters (lysates).

\subsection{TEM Analysis}

For each phage a 200 mesh copper grid coated with carbon-stabilizer formvar was inserted into a tube for airfuge (Beckman), filled with $120 \mu \mathrm{L}$ of each lysate, centrifuged at $20 \mathrm{psi}$ for $15 \mathrm{~min}$ and negative stained with $2 \%$ phosphotungstic acid. Each sample was then observed with TEM EM $900 \mathrm{~T}$ (Zeiss) between 12000x and 80000x magnification.

\section{Results}

The ultrastructure analysis of the three bacteriophages delivered the following results:

$\Phi$ Apr-1: icosahedral-isometric head of about $50 \mathrm{~nm}$ diameter. Thin, long, non-contractile, flexible tail of about $110 \mathrm{~nm}$ in length. Total phage length is about $160 \mathrm{~nm}$. From the analysis of these data phage $\Phi$ Apr-1 was located in the Caudovirales order, Siphoviridae 
family [34], Group B, Morphotype B1 [35]. It is a double stranded DNA virus (Fig. 1).

ФIZSAM-1: icosahedral-isometric head of about 60 $\mathrm{nm}$ in diameter. Long, non-contractile and flexible tail of about $170 \mathrm{~nm}$ in length. Total phage length is about $230 \mathrm{~nm}$. Also this bacteriophage is related to Caudovirales order, Siphoviridae family [34], Group B, Morphotype B1 [35] and it is therefore a double stranded DNA virus (Fig. 2).

$\Phi$ P100: icosahedral-isometric head of about $80 \mathrm{~nm}$ in diameter. Neck of about $20 \mathrm{~nm}$ in length connected to a long, rigid and contractile tail of about $90 \mathrm{~nm}$ lengths. The tail is constituted of an internal tube and of a clearly visible external contractile sheath. The total phage length is about $190 \mathrm{~nm}$. Also base-plate and the tail-tube protruding from the contracted tail were clearly identified. The different pattern of this phage's tail located it in the Myoviridae family of the Order Caudovirales [34], Group A, Morphotype A1 [35]. This is also a double stranded DNA virus (Fig. $3)$.

\section{Discussion}

TEM contributes to a high level of phage classification. Nature and organization of phage genetic material is directly deducted from viral morphology.

When compared with genome analysis, negative staining is much faster to perform and data deriving from virus shape observation provide useful information in short time. In addition to classification, morphological findings are useful also for comparing and selecting bacteriophages to employ in prophylaxis (phage therapy) or in bio-decontamination.

Phages with contractile tail like $\Phi \mathrm{P} 100$ present a higher genetic complexity and different mechanisms of DNA injection during infection when compared with phages having non-contractile tails (e.g. $\Phi$ Apr-1 and IZSAM-1) [36].

Important differences involving assembly pathways can be derived from tail lengths. Bacteriophages with long tails (longer than head diameter) like the three phages speculated in this work, assemble heads and tails separately and then add them together. Instead short-tailed phages (tail shorter then head diameter) add the tail sequentially onto completed heads [36].

Tail lengths give information also about phage stability and resistance in the environment. In fact short and not-tailed phages are generally more resistant while long tails tend to be damaged easier, resulting in loss of infectious activity.

Tailed phages are constituted of double stranded DNA while not-tailed phages have completely different genomic pattern, with single-stranded DNA or RNA [26].

Moreover TEM enables to distinguish between "full" infective virus particles and empty "ghost" particles (Fig. 4). "Ghost" particles, in particular, are represented by viruses after loss of their genetic material as consequence of stress factors (e.g. heat, UV radiations, high pressures) [6]. Empty phages cannot replicate but their lytic activity is still preserved because of the presence of cell wall degrading enzymes (lyis from without) [6, 37].

Some other useful information could arise from the observation of "phage agglomerates". These spatial

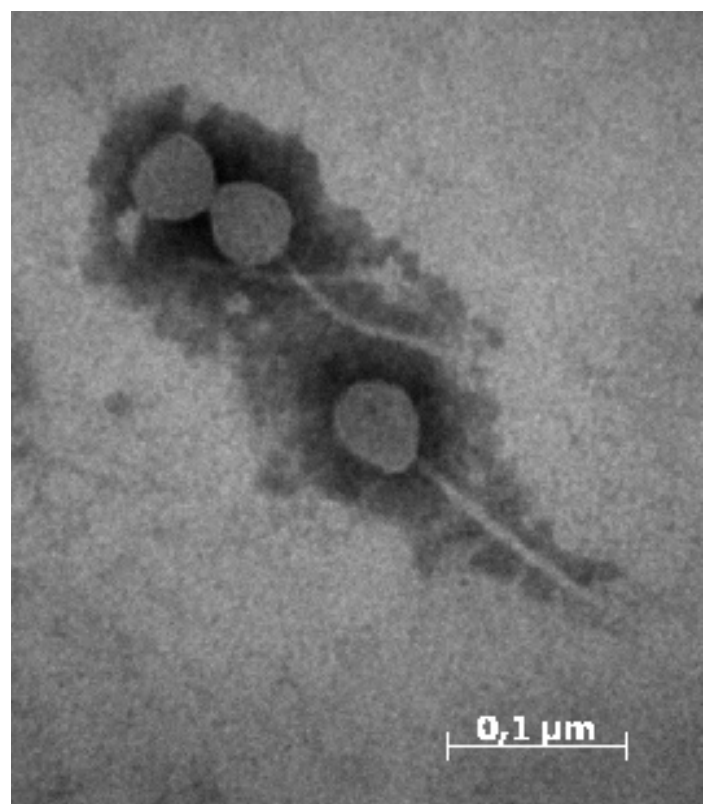

Fig. 1 Phage $\phi$ Apr-1. 


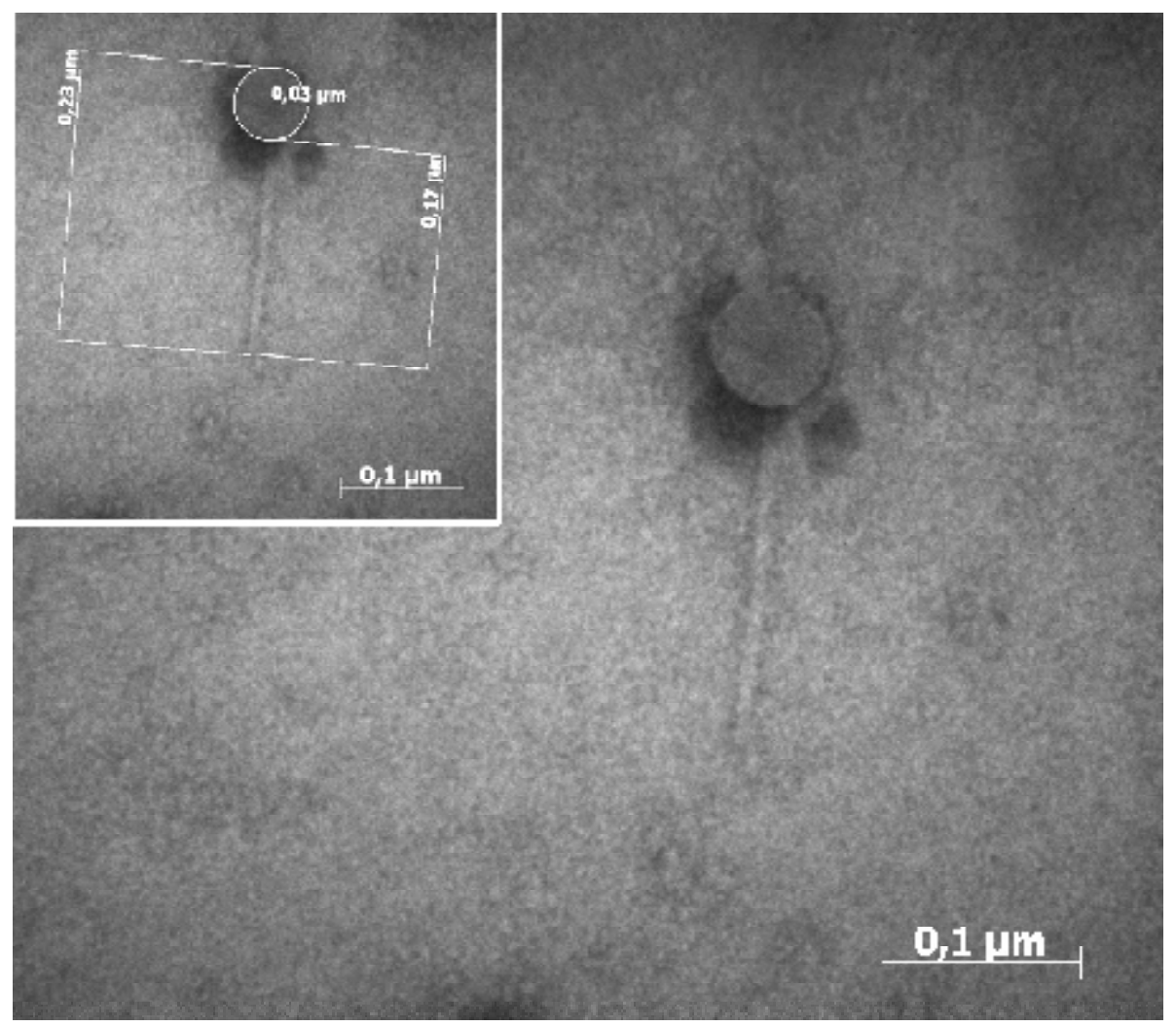

Fig. 2 Phage $\phi I Z S A M-1$.

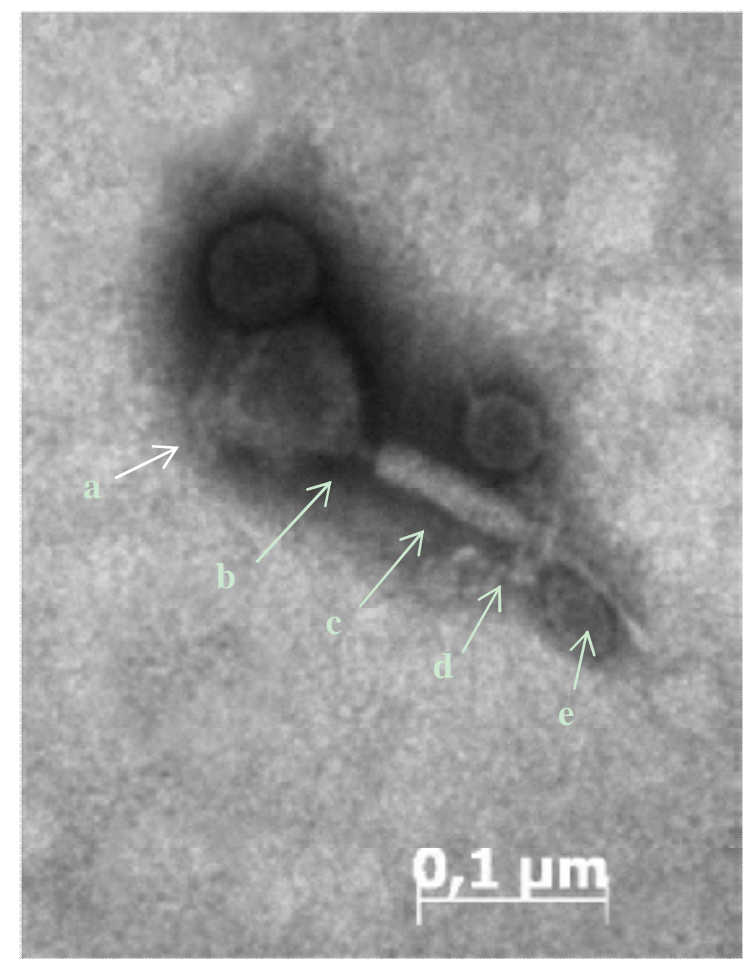

Fig. 3 Phage $\phi \mathrm{P} 100$ with identification of body elements (a-head, b-neck, c-contracted sheath, d-baseplate, e-tail tube). dispositions are consequence of high titre suspensions of large bacteriophages [38], with phage heads adhering together and tails left free towards the inner side of "micelles". These phage suspensions generally present a very low infectivity grade (Fig. 5).

Full/ghost particles and phage agglomerates in particular are useful targets for scientists to screen and evaluate the "quality" of phage lysates.

\section{Conclusions}

Since the discovery of Transmission Electron Microscopy about 70 years ago, bacterial viruses and TEM are deeply linked. Microscopy demonstrated that bacteriophages are viruses with complex sizes and shapes, with intracellular obligate development and unique assembly activities.

TEM provided from the beginning the elements for establishing bacteriophage orders and families and its role is still actively recognised. In fact with the development of new scenarios that locate 

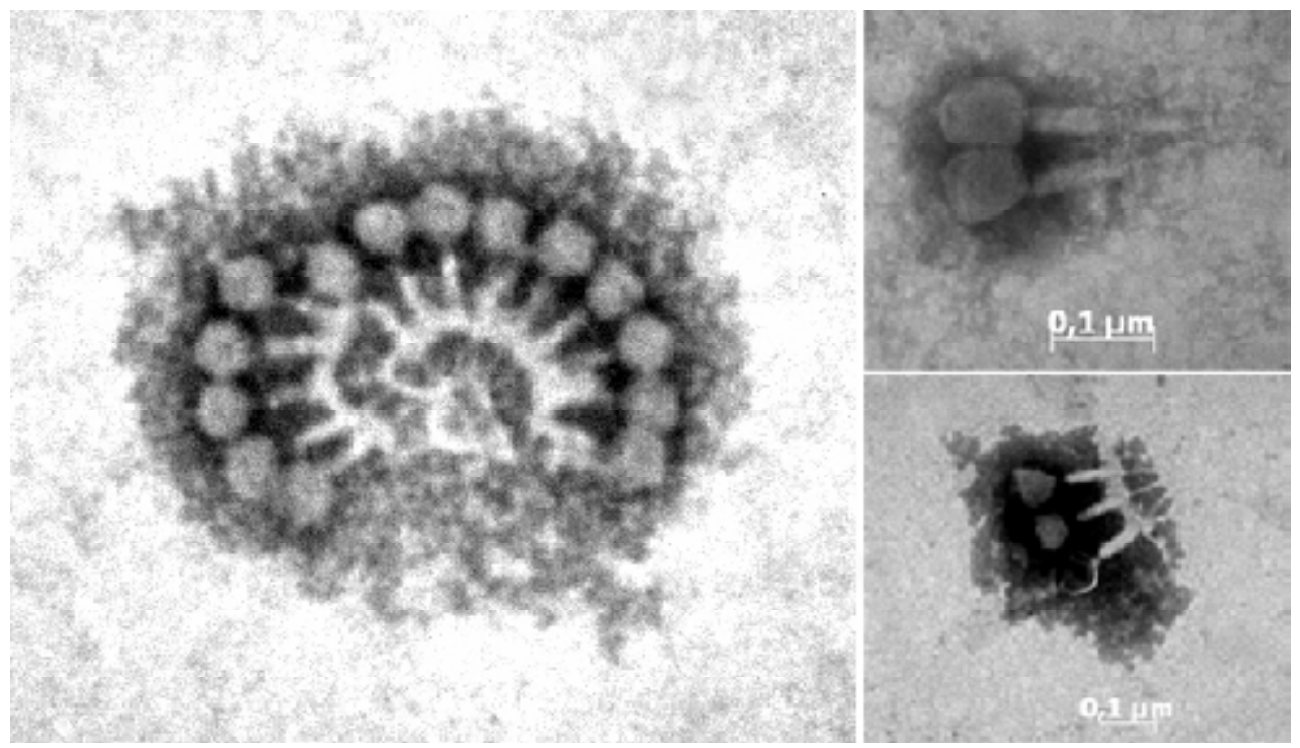

Fig. 4 Bacteriophage $\phi P 100$ "agglomerates".

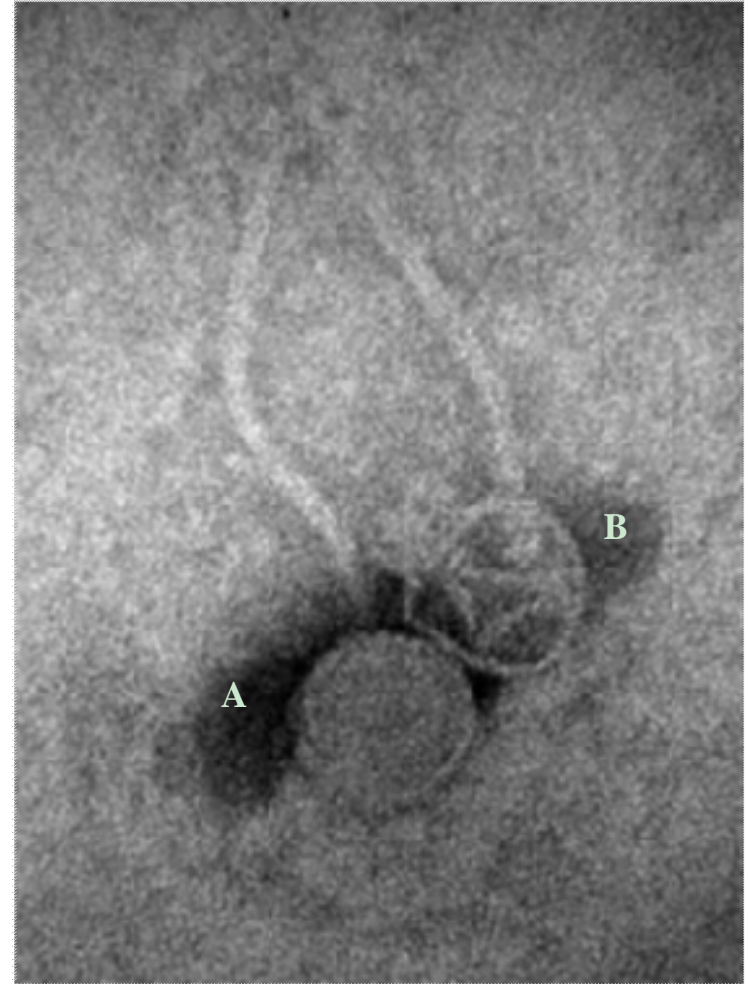

Fig. 5 Phage фIZSAM-1: "full" (A) and "ghost" (B) particles.

bacteriophages in a different framework of applications, shifting from fields of diagnosis to phage-therapy and bio-decontamination, Electron Microscope plays a key role in classifying "novel" phages that are actively being isolated into families.

The features that derive from a punctual viral morphological analysis are useful also for comparing phages and completing their selection process.

Moreover the results confirm bibliographical data about correlation between phages and host present in the same environments, identifying these viruses as good indicators of bacterial contaminations.

\section{References}

[1] Breitbart M., and Rohwer, F. 2005. "Here a Virus, There a Virus, Everywhere the Same Virus?" Trends Microbiol 13: 278-84.

[2] Brussow, H., and Hendrix, R. W. 2002. "Phage Genomics: Small Is Beautiful." Cell 108: 13-6.

[3] Hagens, S., and Loessner, M. J. 2007. “Application of Bacteriophages for Detection and Control of Foodborne Pathogens." Appl. Microbiol. Biotec. 76 (3): 513-9.

[4] Suttle, C. A. 2005. "Viruses in the Sea." Nature 437: 356-61.

[5] Bruttin, A., and Brussow, H. 2005. "Human Volunteers Receiving Escherichia coli Phage T4 Orally: A Safety Test of Phage Therapy." Antimicrob Agents Chemother 2874-8.

[6] EFSA (European Food Safety Authority). 2009. "Scientific Opinion of the Panel on Biological Hazards on a Request from European Commission on the Use and Mode of Action of Bacteriophages in Food Production." The EFSA Journal 1076: 1-26.

[7] Drozevkina, M. S. 1963. "The Present Position in Brucella Phage Research, a Review of the Literature." Bull. Wld Hlth Org 29: 43-57.

[8] Flores, V., López-Merino, A., Mendoza-Hernandez, G., 
and Guarneros, G. 2012. "Comparative Genomic Analysis of Two Brucella phages of Distant Origins." Genomics 99: 233-40.

[9] Frost, J. A., Kramer, J. M., and Gillanders, S. A. 1999. "Phage Typing of Campylobacter Jejuni and Campylobacter coli and Its Use as an Adjunct to Serotyping." Epidemiol. Infect. 123: 47-55.

[10] Hansen, V. M., Rosenquist, H., Baggesen, D. L., Brown, S., and Christensen, B. B. 2007. "Characterization of Campylobacter Phages Including Analysis of Host Range by Selected Campylobacter Penner Serotypes." BMC Microbiol. 7: 90.

[11] Loessner, M. J., and Bisse, M. 1990. "Bacteriophage Typing of Listeria Species.” Appl. Environ. Microbiol. 56: 1912-8.

[12] Loessner, M. J. 1991. "Improved Procedure for Bacteriophage Typing of Listeria Strains and Evaluation of New Phages.” Appl. Environ. Microbiol. 57 (3): 882.

[13] Loessner, M. J., Krause, I. B., Henle, T., and Scherer, S. 1994. "Structural Proteins and DNA Characteristics of 14 Listeria Typing Bacteriophages." J. Gen. Virol. 75: 701-10.

[14] Morris, J. A., Corbel, M. J., and Phillip, J. I. H. I973. "Characterization of Three Phages Lytic for Brucella Species.” J. gen. Virol. 63: 63-73.

[15] Van der Mee-Marquet, N. L., Loessner, M., and Audurier, A. 1997. "Evaluation of Seven Experimental Phages for Inclusion in the International Phage Set for the Epidemiological Typing of Listeria monocytogenes." Appl. Environ. Microbiol. 63: 3374-7.

[16] USDA (United State Department of Agriculture). 2006. "GRAS Notice 000218, GRAS Notification of LISTEX $^{\mathrm{TM}}$ P100 Bacteriophage.” Accessed July 10, 2013. http://www.accessdata.fda.gov/scripts/fcn/gras_notices/7 01456A.PDF.

[17] Connerton, P. L., Timms, A. R., and Connerton I. F. 2011. "Campylobacter Bacteriophages and Bacteriophage Therapy." J. Appl. Microbiol 111: 255-65.

[18] Kutter, E., De Vos, D., Gvasalia, G., Alavidze, Z., Gogokhia, L., Kuhl, S., and Abedon, S. 2010. "Phage Therapy in Clinical Practice: Treatment of Human Infections." Curr. Pharmac. Biotec. 11 (1): 69-86.

[19] Mai, V., Ukhanova, M., Visone, L., Abuladze, T., and Sulakvelidze, A. 2010. "Bacteriophage Administration Reduces the Concentration of Listeria monocytogenes in the Gastrointestinal Tract and Its translocation to Spleen and Liver in Experimentally Infected Mice." Int. J. Microbiol. 1-6.

[20] Hagens, S., and Loessner, M. J. 2010. "Bacteriophage for Biocontrol of Foodborne Pathogens: Calculations and Considerations." Curr. Pharmac. Biotec. 11: 58-68.

[21] Garneau, J. E., and Moineau, S. 2011. "Bacteriophages of
Lactic Acid Bacteria and Their Impact on Milk Fermentations." Microbial Cell Factories 10 (Suppl. 1): S20.

[22] Mahony, J., Ainsworth, S., Stockdale, S., and van Sinderen, D. 2012. "Phages of Lactic Acid Bacteria: Their Role of Genetics in Understanding Phage-Host Interactions and Their Co-evolutionary Processes." Virology 434: 143-50.

[23] Atterbury, R. J., Dillon, E., Swift, C., Connerton, P. L., Frost, J. A., Dodd, C. E. R., Rees, C. E. D., and Connerton, I. F. 2005. "Correlation of Campylobacter Bacteriophage with Reduced Presence of Hosts in Broiler Chicken Ceca." Appl Environ Microbiol 71 (8): 4885-7.

[24] Mandilara, G. D., Smeti, E. M., Mavridou, A. T., Lambiri, M. P., Vatopoulos, A. C., and Rigas, F. P. 2006. "Correlation between Bacterial Indicators and Bacteriophages in Sewage and Sludge." FEMS Microbiol. Lett. 263: 119-26.

[25] Ackermann, H. W. 2012. "Bacteriophages. Part A, Section 1, Chapter 1 Bacteriophage Electron Microscopy." Adv. Virus Res. 84: 1-16.

[26] Bradley D. 1967. "Ultrastructure of Bacteriophages and Bacteriocins.” Bacteriological Reviews 31 (4): 230-314.

[27] Sails, A. D., Wareing, D. R., Bolton, F. J., Fox, A. J., and Curry, A. 1998. "Characterisation of 16 Campulobacter jejuni and Campylobacter coli Typing Bacteriophages." J. Med. Microbiol. 47 (2): 123-8.

[28] Guenther, S., Huwyler, D., Richard, S., and Loessner, M. J. 2009. "Virulent Bacteriophage for Efficient Biocontrol of Listeria monocytogenes in Ready-To-Eat Foods." Appl. Environ. Microbiol. 75 (1): 93-100.

[29] Guenther, S., and Loessner, M. J. 2011. "Bacteriophage Biocontrol of Listeria monocytogenes on Soft Ripened White Mold and Red-Smear Cheeses." Bacteriophage 1 (2): 94-100.

[30] Soni, K. A., Nannapaneni, R., and Hagens, S. 2009. "Reduction of Listeria monocytogenes on the Surface of Fresh Channel Catfish Fillets by Bacteriophage Listex P100." Foodborne Pathogens and Disease 1-8.

[31] Soni, K., and Nannapaneni, R. 2010. "Bacteriophage Significantly Reduces Listeria monocytogenes on Raw Salmon Fillet Tissue.” J. Food Prot. 73 (1): 32-8.

[32] Soni, K. A., Desai, M., Oladunjoye, A., Skrobot, F., and Nannapaneni, R. 2012. "Reduction of Listeria monocytogenes in Queso Fresco Cheese by a Combination of Listericidal and Listeriostatic GRAS Antimicrobials." Int. J. Food Microbiol. 155: 82-8.

[33] Spears, P. A., Suyemoto, M. M., Palermo, A. M., Horton, J. R., Hamrick, T. S., Havell, E. A., and Orndorff, P. E. 2008. "A Listeria monocytogenes Mutant Defective in Bacteriophage Attachment Is Attenuated in Orally Inoculated Mice and Impaired in Enterocyte Intracellular 
Growth.” Infect Immun. 76 (9): 4046-54.

[34] King, A. M. Q., Lefkowitz, E., Adams, M. J., and Carstens, E. B. 2011. Virus Taxonomy: Ninth Report of the International Committee on Taxonomy of Viruses. San Diego: Elsevier Inc.

[35] Ackermann, H. W., and DuBow, M. S. 1986. "General Properties of Bacteriophages." In Viruses of Prokaryotes Boca Raton: CRC Press.

[36] Maniloff, J., and Ackermann, H. W. 1998. "Taxonomy of
Bacterial Viruses: Establishment of Tailed Virus Genera and the Order Caudovirales." Arch. Virol. 143: 10.

[37] Abedon, S. T. 2011. "Lysis from Without." Bacteriophage 1 (1): 46-9.

[38] Anany, H., Chen, W., Pelton, R., and Griffiths, M. W. 2011. "Biocontroll of Listeria monocytogenes and Escherichia Coli O157:H7 in Meat by Using Phage Immobilized on Modified Cellulose Membranes." Appl. Environ. Microbiol. 77 (18): 63-79. 